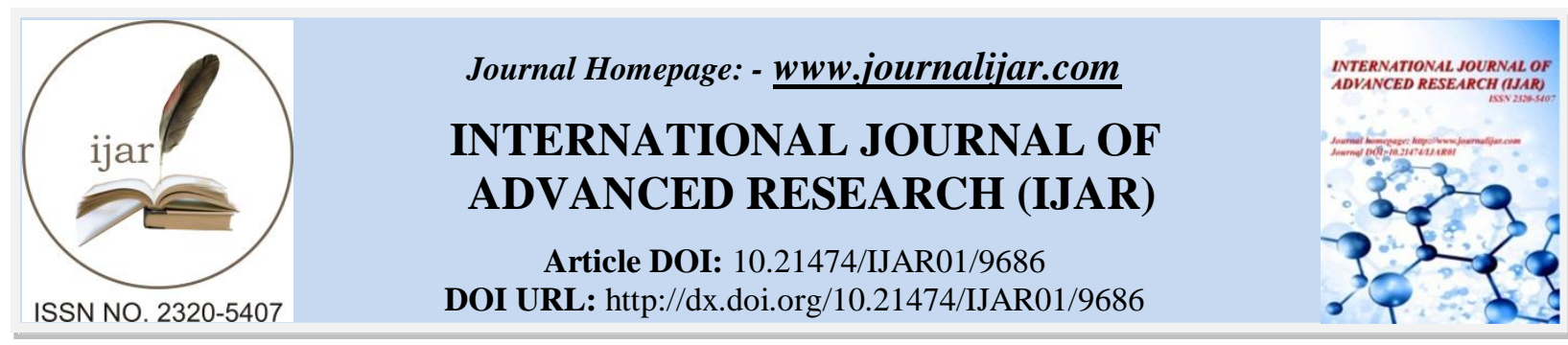

RESEARCH ARTICLE

\title{
A STUDY OF CONGENITAL CATARACT-DIAGNOSIS,MANAGEMENT AND OUTCOMES.
}

\section{Dr. Mukaram G G Khan, Dr. Anjali S Khairnar, Dr Shubha Ghonsikar Jhavar, Dr Ketaki Shah, Dr.} Kaustubh Thakur.

\section{Manuscript Info}

Manuscript History

Received: 06 July 2019

Final Accepted: 08 August 2019

Published: September 2019

Key words:-

Consanguinity, Maternal infections.

\begin{abstract}
Purpose: To study the causes, management and visual outcome of congenital cataract.

Methods: Retrospective study conducted in the tertiary eye care center from January 2008 to December 2015. 16 eyes of 13 children with age ranging from 1 month to 14 years were included in the study after fulfilling the inclusion and exclusion criteria. All the children underwent thorough clinical examination before the surgery. Children underwent Small Incision Cataract Surgery with Intraocular Lens.

Results: 3 children had congenital cataract in both eyes. All 3 were male children. 5 children were born out of consanguineous marriage. Cataract surgery was performed in all the children. The preoperative visual acuity ranged from perception of light to $6 / 24$. After surgery, $50 \%$ ( 8 eyes) had $6 / 60$ to $6 / 18$ vision. The rest of the eyes had a perception of light to $5 / 60$ vision.

Conclusion: Study revealed that consanguinity was one of the aetiological factor and that their visual acuity before surgical intervention was very poor. After surgery the visual acuity improved in the range of $6 / 60$ to $6 / 18$ in $50 \%$ of the children. The Study was taken up in view of bringing out the importance of early surgical intervention in children with congenital cataract and give them a better future. Timely recognition and intervention can eliminate blind years due to childhood cataract as the condition is treatable.
\end{abstract}

Copy Right, IJAR, 2019,. All rights reserved.

\section{Introduction:-}

Childhood cataract is responsible for $5 \%$ to $20 \%$ of blindness in children worldwide and for an even higher percentage of childhood visual impairment in developing countries. The prevalence of childhood cataract varies from 1.2 to 6.0 cases per 10,000 infants. ${ }^{1,2,3}$ Hence the timely removal of cataract followed by prompt visual rehabilitation is of utmost importance in children. ${ }^{4,5}$ Important causes of childhood cataract include genetic disorder, intrauterine infection, metabolic disorders, drug induced, trauma and other ocular disorders like aniridia, microphthalmia, persistent hyperplastic primary vitreous and anterior segment cleavage syndrome. ${ }^{6,7}$

Cataract in children may be present at birth (congenital cataract) or may appear anywhere during the first few years of life (developmental cataract) . 


\section{Aim-}

1. To study the number of cases diagnosed as congenital cataract in ophthalmology department of a tertiary care hospital.

2. To determine the etiology of congenital cataract.

3. To study the outcomes of the cataract surgery performed in unilateral and bilateral cataract in the age group 0 to 14 years.

\section{Materials and Methods:-}

This is a retrospective study conducted in a government medical college in which 13 children with age ranging from 0 month to 14 years who were admitted and operated for congenital cataract during January 2008 to December 2015 were included.

\section{Inclusion criteria}

1. Children with age less than 14 years

2. Children with vision not less than Hand Movements

3. Children born of of both consanguineous and non consanguineous marriages.

\section{Exclusion criteria}

1. Children with age more than 14 years

2. Children with vision less than Hand Movements.

3. Children with history of trauma to the eye after birth.

4. Children with any other ocular anomaly present at birth.

A detailed history, birth history, family history of congenital cataract was asked.Birth history included history of consanguinity, maternal infection (TORCH) in first trimester of pregnancy, gestational age and birth weight, birth trauma, supplemental oxygen therapy in perinatal period and developmental milestones.

Visual status in terms of ambulation in familiar and unfamiliar surroundings as well as behavioural pattern and school performance history was asked.

Examination involved-

1. Recording of visual acuity and fixation pattern in each eye

2. Refraction

3. Cover-uncover test / Hirschbergs test

4. Nystagmus evaluation

5. Slit lamp examination.

6. Ultrasound B-scan in a case of dense cataract

Apart from ophthalmic evaluation, patient was examined to see for any facial dysmorphic features or other systemic associations to rule out syndromic anomalies.

TORCH titre was done whenever indicated.

Patients were operated for congenital cataract after getting fitness for surgery under anesthesia. Intraocular lens power calculation, intraocular pressure measurement and ophthalmoscopic examination was done during evaluation under anesthesia. Superior small incision cataract surgery with posterior chamber intraocular lens implantation was done in all patients.Postoperative steroid antibiotic drops were prescribed in tapering doses along with cycloplegics for 1 month.

In children having bilateral cataract, second eye was operated after a period of 1 month.

A thorough and comprehensive post operative examination was done for each patients starting from 1st post operative day till the date of discharge from the hospital which was usually the $3^{\text {rd }}$ day. After that follow up was done on day 15 and 1 month.

On 1 month follow up visit, glass prescription was given. 


\section{Results:-}

The results of the above said study are as follows

Table 1:-

\begin{tabular}{|l|l|l|}
\hline Gender & No.of patients & No of patients in percentage \\
\hline Male & 8 & 61.54 \\
\hline Female & 5 & 38.46 \\
\hline
\end{tabular}

In this study, 16 eyes of 13 patients with congenital cataract were operated. The maximum number of patients is in the age group between 7 to 14 years. The least number of patients was found in the age group between $1 \mathrm{month}-$ 6months.

Table 2:-

\begin{tabular}{|l|l|l|}
\hline Age group & Number & percentage \\
\hline 1 month to 6 months & 1 & 7.7 \\
\hline 6 month-12 month & 2 & 15.38 \\
\hline 1 year to 6 years & 4 & 30.77 \\
\hline 7 years to 14 years & 6 & 46.15 \\
\hline
\end{tabular}

History of consanguinity revealed consanguineous marriages of parents of 5 children.

Table 3:-

\begin{tabular}{|l|l|l|}
\hline Consanguinity status & Number & Percentage \\
\hline Born of Consanguineous marriage & 5 & 38.46 \\
\hline Born of non consanguineous marriage & 8 & 61.54 \\
\hline
\end{tabular}

Table 4:-Visual acuity was checked for patients between the age 1 year to 14 years with Snellen's or appropriate charts for age.

\begin{tabular}{|l|l|l|l|l|}
\hline Sr no & $\begin{array}{l}\text { Preoperative visual } \\
\text { acuity }\end{array}$ & Number of eyes & $\begin{array}{l}\text { Postoperative visual } \\
\text { acuity }\end{array}$ & Number of eyes \\
\hline 1 & HM & $4(25 \%)$ & HM & $3(18.75 \%)$ \\
\hline 2 & FCCF & $6(37.5 \%)$ & FCCF & $5(31.25 \%)$ \\
\hline 3 & $5 / 60-1 / 60$ & $4(25 \%)$ & $5 / 60-1 / 60$ & $6(37.5 \%)$ \\
\hline 4 & $6 / 60-6 / 24$ & $2(12.5 \%)$ & $6 / 60-6 / 18$ & $2(12.5 \%)$ \\
\hline
\end{tabular}

The surgery was performed under general anaesthesia.

All of the children underwent SICS with IOL.

After 1 month, visual acuity with spectacle correction was checked and glass prescription was given.

At 1 month postoeratively, 2 children with bilateral cataracts had vision of hand movement in one eye and counting finger close to face in the other eye. Third child with bilateral cataract had counting finger close to face in both his eyes. Vision improved to 1/60-5/60 in 6 children and upto 6/18 in 4 children.

Table 5:-

\begin{tabular}{|l|l|l|}
\hline Sr no & Visual acuity with correction & Number of eyes \\
\hline 1 & HM & $2(12.5 \%)$ \\
\hline 2 & FCCCF & $4(25 \%)$ \\
\hline 3 & $1 / 60-5 / 60$ & $6(37.5 \%)$ \\
\hline 4 & $6 / 60-6 / 18$ & $4(25 \%)$ \\
\hline
\end{tabular}




\section{Results:-}

3 children had congenital cataract in both eyes. All 3 were male children. Consanguinity was present in parents of 5 children and parents of 8 children were not related. Surgery was performed in all the children. The preoperative visual acuity ranged from perception of light to $6 / 24$. After surgery, $50 \%$ (8 eyes) had $6 / 60$ to $6 / 18$ vision. The rest of the eyes had a perception of light to $5 / 60$ vision.

\section{Discussion:-}

In the present study, the clinical and surgical data of 16 eyes of 13 children with congenital cataract patients done at government medical college between January 2008 to December 2015 was assessed.

In order to visually rehabilitate an infantile eye after cataract extraction, the eye must be focused optically and therapy must be initiated to treat and prevent further development of amblyopia. ${ }^{8,9,10}$

The study done by Forbes et al on the surgical management of cataract in children shows the need for early surgery at or before 6 weeks of age and before the development of binocular vision which will give a good visual prognosis. ${ }^{11}$ This inference coincides with the present study.

A case report presented by Ruth et al mentions about cataract extraction with IOL implantation in a 8 week old child. The child had better vision in the operated eye than the normal eye. This also matches the present study with regard to postoperative visual prognosis.

The real challenge starts after the cataract surgery as the child is left with gross refractive error, which can lead to the development of amblyopia if not corrected in time. ${ }^{12}$ Achieving a good visual outcome following cataract surgery in children remains difficult,requiring extra effort and patience on the part of the ophthalmologist and good compliance from the parents. ${ }^{13,14,15}$

Consanguinity was present in 5 children and parents of 8 children were not related.

Surgery was performed in all the children - Small Incision Cataract Surgery with Intra Ocular lens implantation.

The preoperative visual acuity ranged from Perception of light to 6/24.

At 1 month postoeratively visual acuity was $6 / 60-6 / 18$ in $25 \%$ of eyes (4 eyes ) and $1 / 60$ tp $5 / 60$ in $37.5 \%$ of eyes ( 6 eyes).

\section{Conclusion:}

Study revealed that consanguinity was one of the major contributing factor in the etiology of congenital cataract and that their visual acuity before surgical intervention was very poor. After surgery the visual acuity improved in the range of $6 / 60$ to $6 / 18$ in 50\% of the children. The Study was taken up in view of bringing out the importance of early surgical intervention in children with congenital cataract and give them a better future. Timely recognition and intervention can eliminate blind years due to childhood cataract as the condition is treatable.

\section{Summary}

This retrospective study entitled "A study of congenital cataract-diagnosis,management and outcomes."which included 16 eyes of 13 children with congenital cataract revealed that consanguinity of various grades was the aetiological factor and that their visual acuity before surgical intervention was very poor. After surgery the visual acuity improved in the range of $6 / 60$ to $6 / 18$ in $25 \%$ of the children.

The management of congenital cataract is complex, and should only be carried out in specialist centers. However, every eye worker can play a role by assisting with case finding and follow up.

Timely recognition and intervention can eliminate blind years due to childhood cataract as the condition is treatable. 


\section{References:-}

1. Forbes, Guo. Pediatric Ophthalmology 2006; P143-151.

2. Foster A, Gilbert C. Epidemiology of visual impairment in children. Taylor D eds. Paediatric Ophthalmology. 1997; 2nd ed. 3-12. Blackwell Science London.

3. Taylor D. The Doyne Lecture. Congenital cataract: the history, the nature and the practice. Eye (Lond). 1998;12(1):9-36.

4. Wilson ME, Pandey SK, Thakur J. Paediatric cataract blindness in the developing world: surgical techniques and intraocular lenses in the new millennium. Br J Ophthalmol. 2003;87(1):14-19.

5. Zetterstrom C, Lundvall A, Kugelberg M. Cataracts in children. J Cataract Refract Surg. 2005;31(4):824-840.

6. Foster A, Gilbert C. Epidemiology of childhood blindness. Eye (Lond). 1992;6(2):173-176.

7. Lambert SR, Drack Av. Infantile cataracts. Surv ophthalmol 1996;40(6);427- 458.

8. Birch EE, Stager DR. The critical period for surgical treatment of dense congenital unilateral cataract. Invest Ophthalmol Vis Sci. 1996;37(8):1532- 1538.

9. Taylor D, Wright KW, Amaya L, Cassidy L, Nischal K, Russell-Eggitt I. Should we aggressively treat unilateral congenital cataracts? Br J Ophthalmol. 2001;85(9): 1120-1126.

10. Awaya S, Miyake S. Form vision deprivation amblyopia: further observations. Graefes Arch Clin Exp Ophthalmol. 1988;226(2):132-136.

11. Ledoux DM, Trivedi RH, Wilson ME Jr., Payne JF. Pediatric cataract extraction with intraocular lens implantation: Visual acuity outcome when measured at age four years and older JAAPOS. 2007;11(3):218-224.

12. Lambert SR. Treating amblyopia in aphakia and pseudophakic children. Amer Orthoptic Jrnl. 2007;57(1):35-40.

13. Gouws P, Hussin HM, Markham R HC. Long term results of primary posterior chamber intraocular lens implantation for congenital cataract in the first year of life. Br J Ophthalmol. 2006;90(8): 975-978.

14. Dahan E, Salmenson BD. Pseudophakia in children: precautions, technique, and feasibility. J Cataract Refract Surg. 1990;16(1):75-82.

15. Kugleberg U. Visual acuity following treatment of congenital cataracts. Doc Ophthalmol. 